\title{
QUANTUM WELL THERMOELECTRICS FOR CONVERTING WASTE HEAT TO ELECTRICITY
}

\author{
DOE AWARD DE-FC26-03NT41974 \\ QUARTERLY TECHNICAL PROGRESS REPORT \\ REPORTING PERIOD 9-1-2003 THROUGH 12-31-2003
}

\author{
Submitted By \\ Hi-Z Technology, Inc. \\ 7606 Miramar Road, Suite 7400 \\ San Diego, CA 92126
}

\section{Prepared By}

Dr. Saeid Ghamaty, P.I

Phone (858) 695-6660

FAX (858) 695-8870

Issued: January 2004 


\section{DISCLAIMER}

"This report was prepared as an account of work sponsored by an agency of the United States Government. Neither the United States Government nor any agency thereof, nor any of their employees, makes any warranty, express or implied, or assumes any legal liability or responsibility for the accuracy, completeness, or usefulness of any information, apparatus, product, or process disclosed, or represents that its use would not infringe privately owned rights. Reference herein to any specific commercial product, process, or service by trade name, trademark, manufacture, or otherwise does not necessarily constitute or imply its endorsement, recommendation, or favoring by the United States Government or any agency thereof. The views and opinions of authors expressed herein do not necessarily state or reflect those of the United States Government or any agency thereof.” 


\begin{abstract}
New thermoelectric materials using Quantum Well (QW) technology are expected to increase the energy conversion efficiency to more than $25 \%$ from the present $5 \%$, which will allow for the low cost conversion of waste heat into electricity.

Hi-Z Technology, Inc. has been developing QW technology over the past six years. It will use Caterpillar, Inc., a leader in the manufacture of large scale industrial equipment, for verification and life testing of the QW films and modules.

Other members of the team are Pacific Northwest National Laboratory, who will sputter large area QW films. The Scope of Work is to develop QW materials from their present proof-ofprinciple technology status to a pre-production level over a proposed three year period. This work will entail fabricating the QW films through a sputtering process of $50 \mu \mathrm{m}$ thick multi layered films and depositing them on 12 inch diameter, $5 \mu \mathrm{m}$ thick Si substrates.

The goal in this project is to produce the technology for fabricating a basic 10-20 watt module that can be used to build up any size generator such as: a 5-10 kW Auxiliary Power Unit (APU), a multi kW Waste Heat Recovery Generator (WHRG) for a class 8 truck or as small as a 10-20 watt unit that would fit on a daily used wood fired stove and allow some of the estimated 2-3 billion people on earth, who have no electricity, to recharge batteries (such as a cell phone) or directly power radios, TVs, computers and other low powered devices.

In this quarter Hi-Z has continued fabrication of the QW films and also continued development of joining techniques for fabricating the $\mathrm{N}$ and $\mathrm{P}$ legs into a couple. The upper operating temperature limit for these films is unknown and will be determined via the isothermal aging studies that are in progress. We are reporting on these studies in this report. The properties of the QW films that are being evaluated are Seebeck, thermal conductivity and thermal-to-electricity conversion efficiency.
\end{abstract}




\section{TABLE OF CONTENTS}

1 List of Graphics

2 Introduction

3 Executive Summary

4 Progress by Tasks/Experimental/Results and Discussions/Conclusions

$5 \quad$ References 


\section{List of Graphics}

Figure 1A. Samples for Testing Contact Resistance

Figure 1B. QW Experimental $11 \mu \mathrm{m}$ Thick Couple

Figure 2. Measured Effective Resistivity Vs. Temperature

Figure 3. Measured Effective Seebeck Vs. Temperature

Figure 4. Measured Effective Thermal-K Vs. Temperature

Figure 5. QW Couple Efficiency Vs. Temperature

Figure 6. Experimental Setup for Efficiency and TE Properties Measurements

Figure 7. PNNL Experimental Results

\section{Introduction}

Hi-Z is making progress on the development of a new type of thermoelectric conversion device called Quantum wells (QW). Hi-Z has recently measured power and efficiency demonstrating a QW couple conversion efficiency of $14 \%$ using a $11 \mu \mathrm{m}$ QW film deposited on a $5 \mu \mathrm{m}$ thick silicon substrate. The thickness of the films, area of deposition, and the method of joining $\mathrm{N}$ and p legs is the substance of this research and development effort.

\section{Executive Summary}

In this quarter Hi-Z started fabrication of thicker $(>11 \mu \mathrm{m})$ QW films and also started development of joining techniques for fabricating the $\mathrm{N}$ and $\mathrm{P}$ legs into a couple. The upper operating temperature limit for these films is unknown and will be determined via the isothermal aging studies that are in progress. Fabrication of the films from the present $11 \mu \mathrm{m}$ with an efficiency $14 \%$ to the $30-50 \mu \mathrm{m}$ range with a possible efficiency of $\sim 21 \%$, is expected to be difficult since the added layers could induce stresses that will lead to warping or cracking of the films and the Si substrate. The sputtering techniques may have to be modified to develop these much thicker films. We will be reporting on these studies in the future.

\section{Progress by Tasks/Experimental/Results and Discussion/Conclusions}

\section{Task 1, QW Film Fabrication}

The upper operating temperature limit for these films is unknown and will be determined via the isothermal aging studies that are in progress. Fabrication of the films from the present $11 \mu \mathrm{m}$ with an efficiency $14 \%$ to the $30-50 \mu \mathrm{m}$ range with a possible efficiency of $\sim 21 \%$, is expected to be difficult since the added layers could induce stresses that will lead to warping or cracking of the films and the Si substrate. The sputtering techniques may have to be modified to develop these much thicker films. We will be reporting on these studies in the future.

\section{Task 2}

Thermal stability tests are in progress. See chart below. 


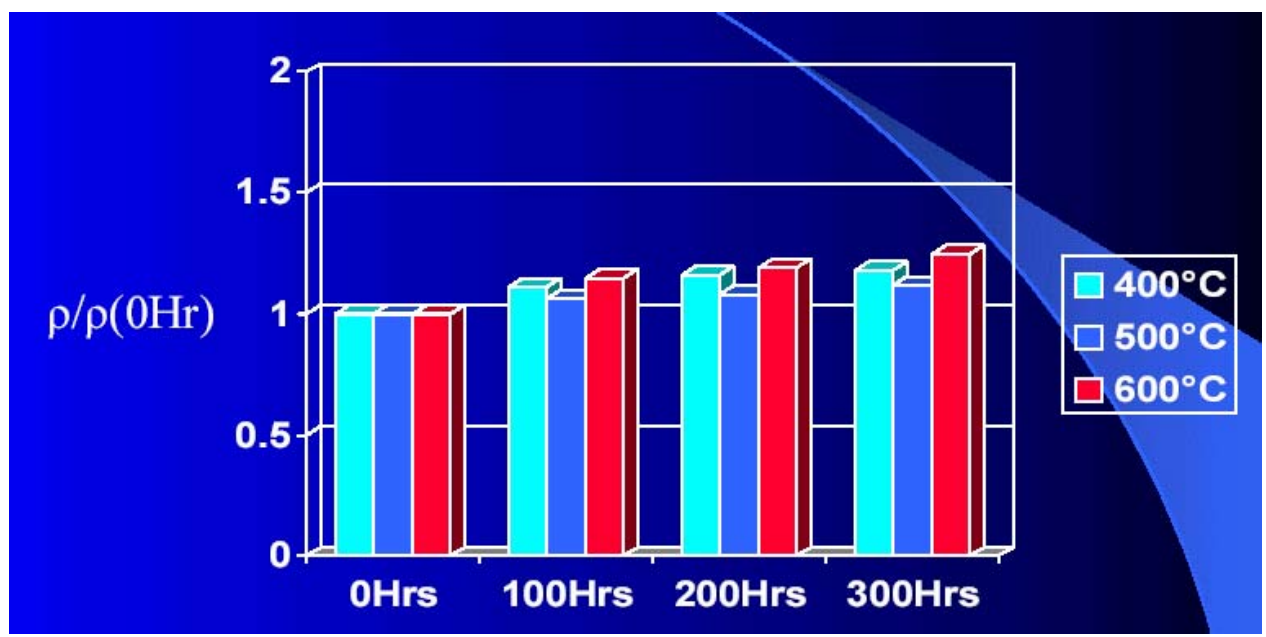

\section{Task 3}

Module fabrication and couple fabrication have started as below.

\section{Joining $\mathbf{N}$ and $\mathbf{P}$ legs}

Presently the joints are being made by silver epoxy and while this may be acceptable for low temperature service, long term low resistance stable bonds are needed for high temperature generation. Critical to this need is that each $100 \AA$ thick layer needs to be metallurgically contacted or "wetted" to obtain the lowest possible contact resistance. With the above goal in mind, following technologies are being investigated and will be pursued:

1. Conductive epoxies

2. Conductive inks

3. Metal spraying

Different brands of the epoxies are being tested, along with conductive inks from Dupont. Figure 1A shows typical test samples.

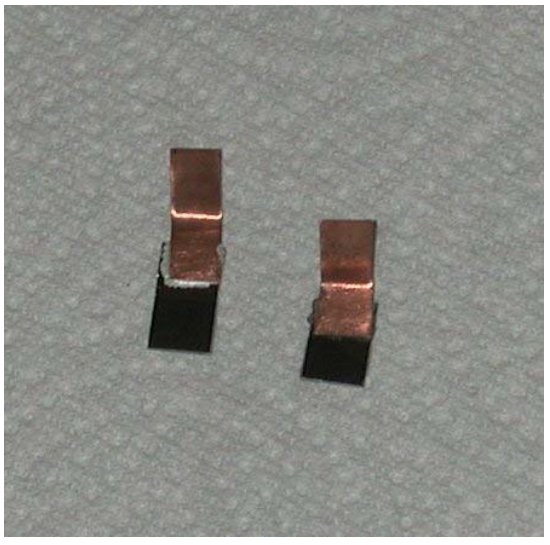

Figure 1A. Samples for Testing Contact Resistance

Table 1, below, shows the contact resistance for the different epoxies. The conductive inks and metal sprayed samples are being fabricated and results will be reported later. After all the 
samples are fabricated and tested at room temperature as well as elevated temperature ( 400 $600^{\circ} \mathrm{C}$ ), then, the method with the lowest contact resistance will be used for the QW module fabrication.

Table 1. Contact Resistance for Various Epoxies

\begin{tabular}{|l|l|}
\hline Conductive epoxy & Contact resistance \\
\hline $\begin{array}{l}\text { Circuit Works CW2400 } \\
\text { Silver epoxy }\end{array}$ & 1.39 to $2.76 \mathrm{~m} \Omega$ \\
\hline $\begin{array}{l}\text { Aremco } 597 \mathrm{~A} / \mathrm{C} \\
\text { Silver filled }\end{array}$ & 2.83 to $5.19 \mathrm{~m} \Omega$ \\
\hline $\begin{array}{l}\text { Aremco } 598 \mathrm{~A} / \mathrm{C} \\
\text { Nickel filled }\end{array}$ & 3.14 to $3.48 \mathrm{~m} \Omega$ \\
\hline
\end{tabular}

\section{Area Control}

The area of deposition needs to be increased substantially so these films can be fabricated economically. Deposition studies will be carried out in similar fashion as noted for the thickness studies to obtain uniform layers over the whole area of deposition. This task will be performed by PNNL, which we visited on March 9, 2004 to initiate this task.

\section{Evaluation of films}

The thermoelectric properties, resistivity ( $\rho)$, Seebeck coefficient $(\alpha)$ as well as thermal conductivity ( $\kappa$ ) of the $11 \mu \mathrm{m}$ thick films $\mathrm{N}$ and $\mathrm{P}$ materials that comprise the couple (shown in the Figure 1B) were measured recently. The results are shown in the Figures 2, 3 and 4. All the properties were measured experimentally for both the film and substrate together, and represent an "effective", film+substrate, or composite, with no data correction. In other words, the properties of the $5 \mu \mathrm{m}$ thick substrate have not been subtracted out of the data shown in Fig. 2, 3 and 4. The experimental setup is shown in a sketch in Figure 6. All the properties were measured on the same sample except for the thermal conductivity, which was measured on a different sample but from the same batch, using the three omega method. 


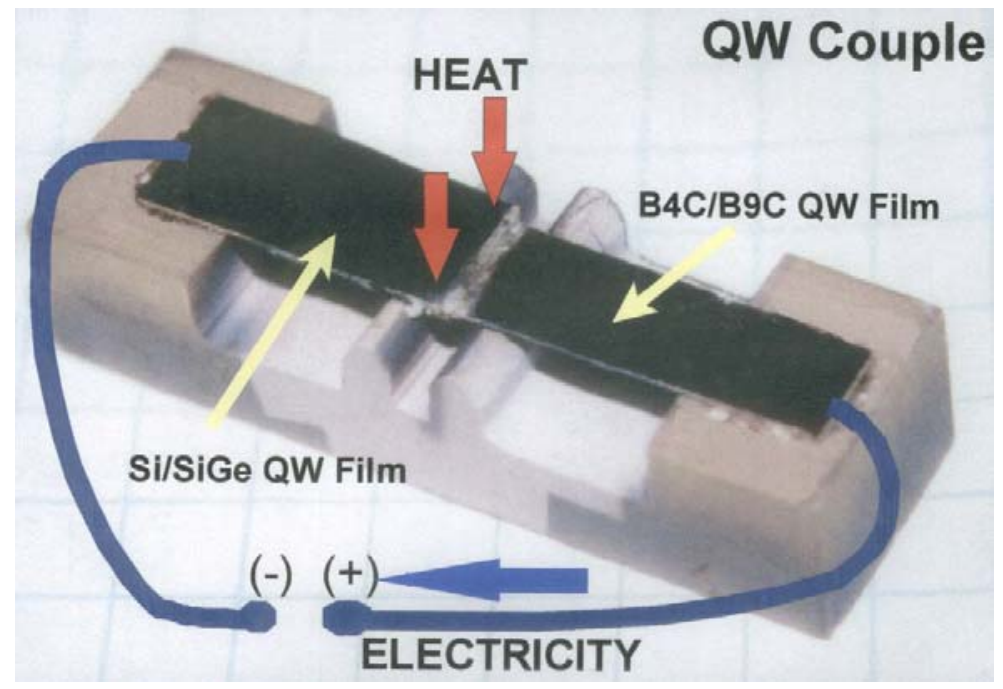

Figure 1B. QW Experimental 11 $\mu$ m Thick Couple

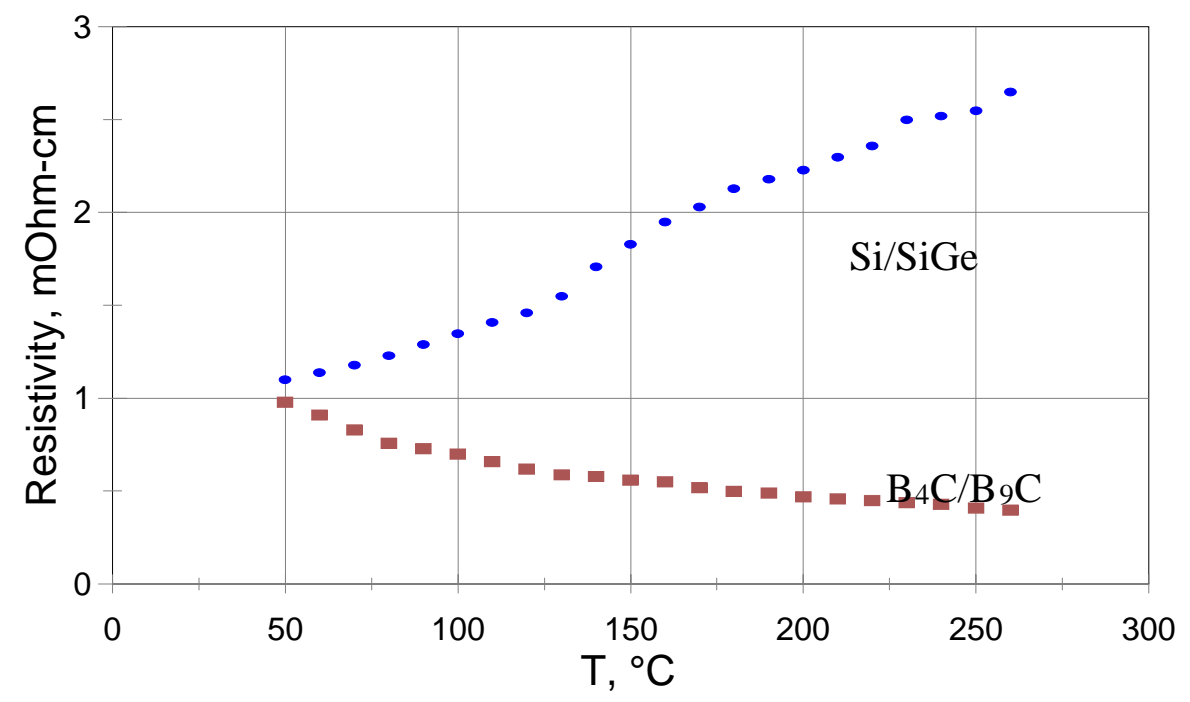

Figure 2. Measured Effective Resistivity Vs Temperature 


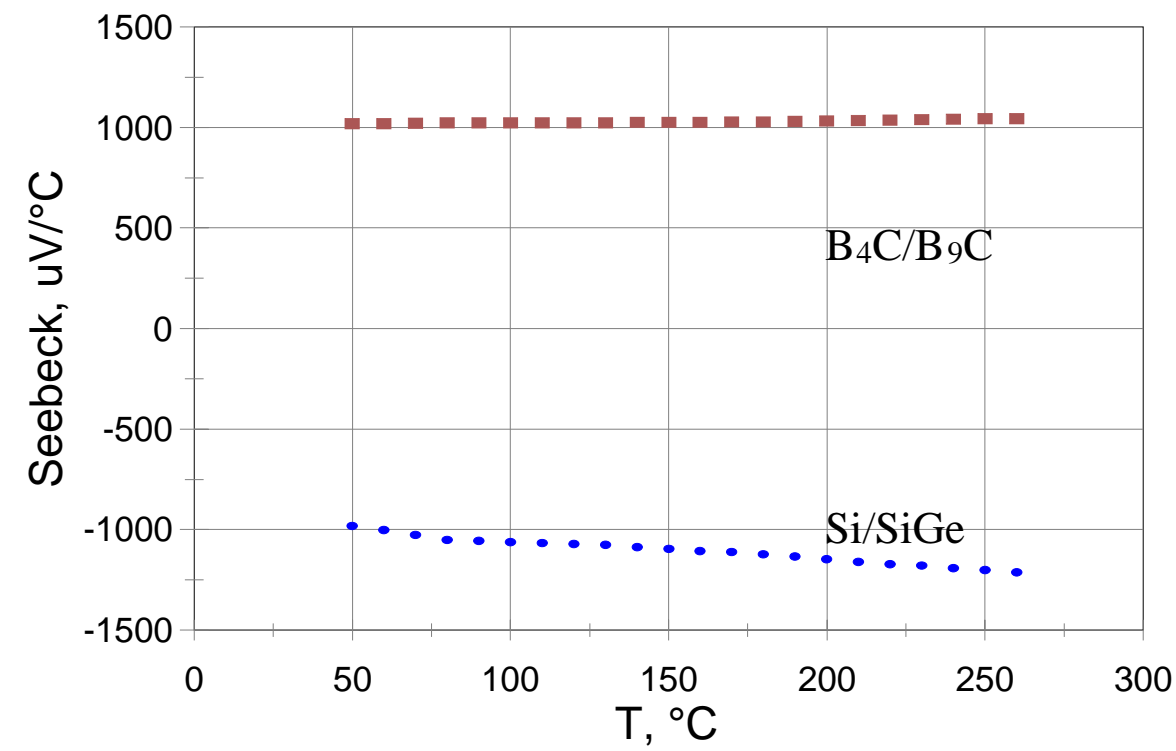

Figure 3. Measured Effective Seebeck Vs Temperature

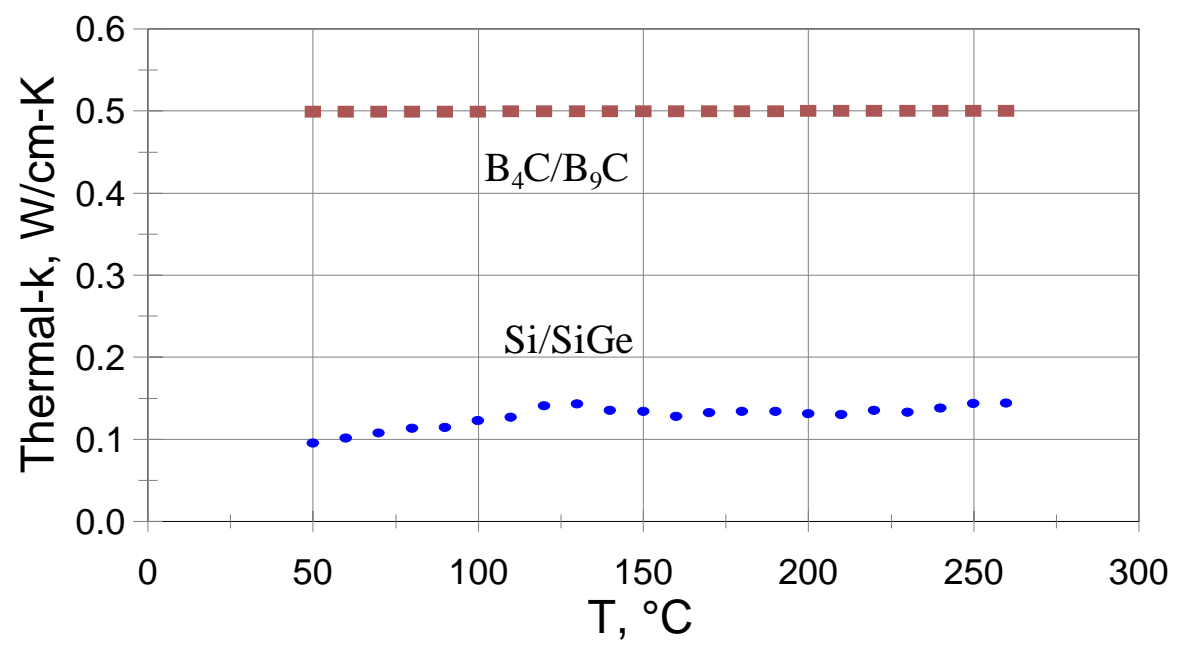

Figure 4. Measured Effective Thermal-k Vs Temperature

These measured properties, were then used to calculate the efficiency of the couple, and the result is shown in Figure 5. This efficiency calculation is in close agreement with the direct efficiency measurement shown in the Figure 5. 


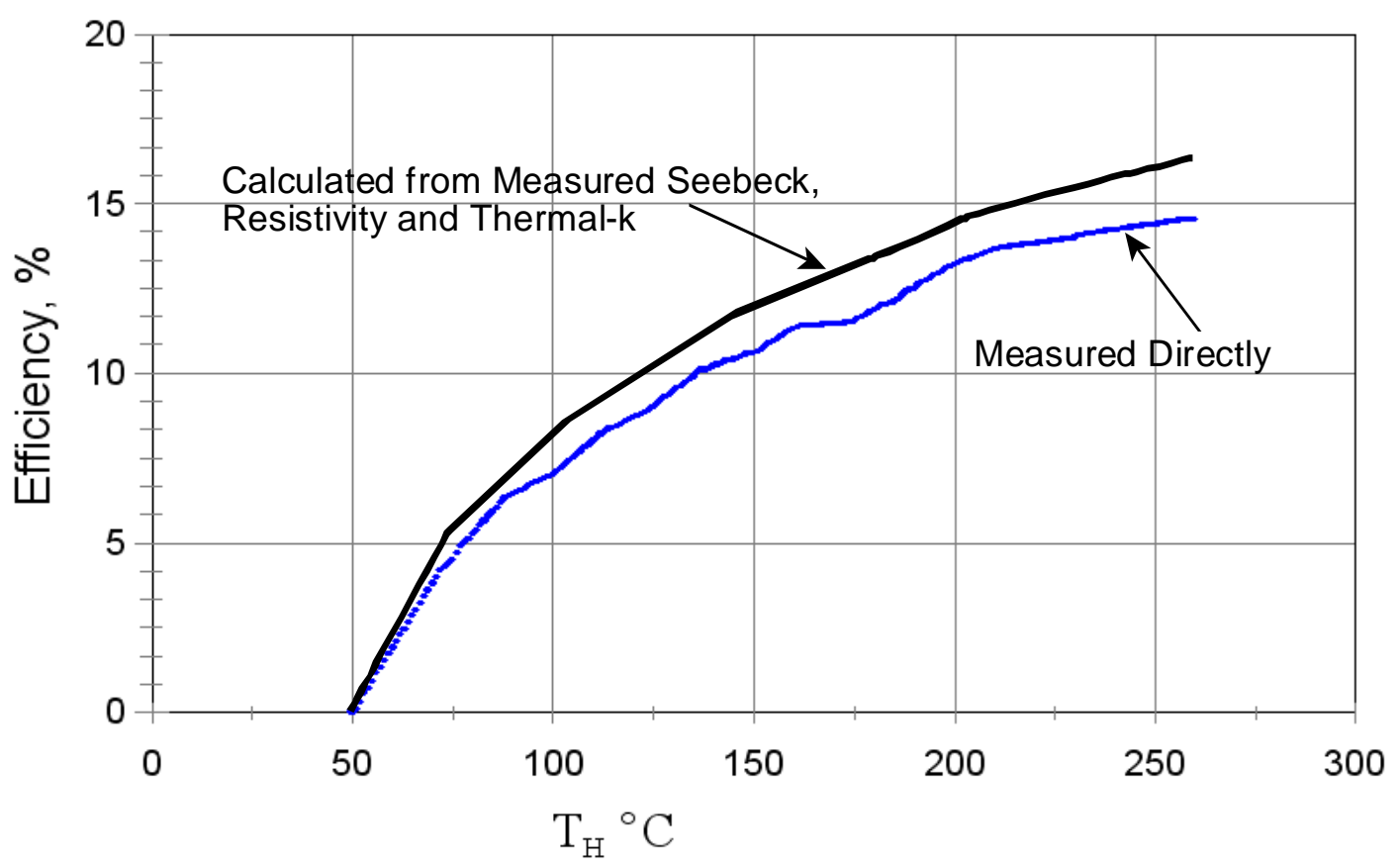

Figure 5. QW Couple Efficiency Vs Temperature

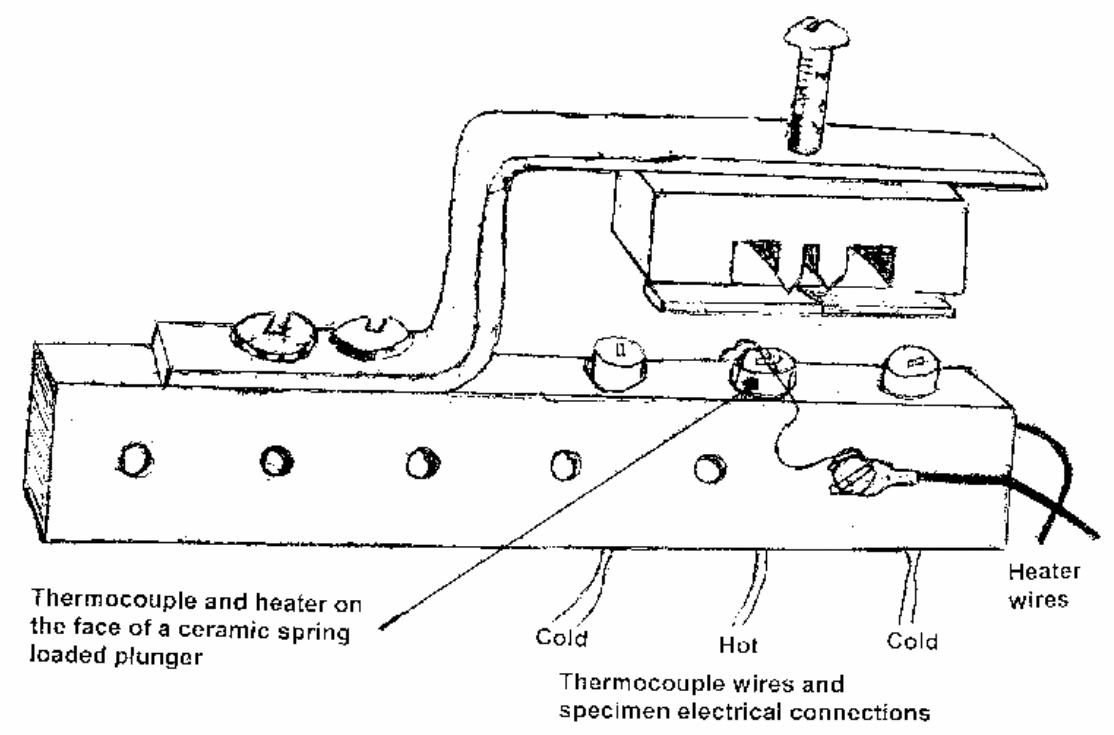

Figure 6. Experimental Setup for Efficiency and TE Properties Measurements

The higher value of the calculated efficiency (Fig. 5) over the experimental value can be explained, since the efficiency measurements were not corrected for any thermal losses. At higher temperatures, the thermal losses will be higher (thermal losses are mostly radiative and are proportional to $\mathrm{T}^{4}$ ), therefore, the calculated efficiency will deviate more at the higher temperatures from the uncorrected experimental curve. This is shown clearly in Figure 5. 


\section{Samples fabricated and measured by PNNL}

Pacific Northwest National Laboratory (PNNL) with funding from DOE has fabricated and measured $\mathrm{B}_{4} \mathrm{C} / \mathrm{B}_{9} \mathrm{C}$ and $\mathrm{Si} / \mathrm{SiGe}$ samples. These samples were fabricated in the same way as the Hi-Z samples. The measured resistivity and Seebeck coefficient (done at PNNL) shows similar values as the Hi-Z samples. PNNL results are shown in Figure 7.

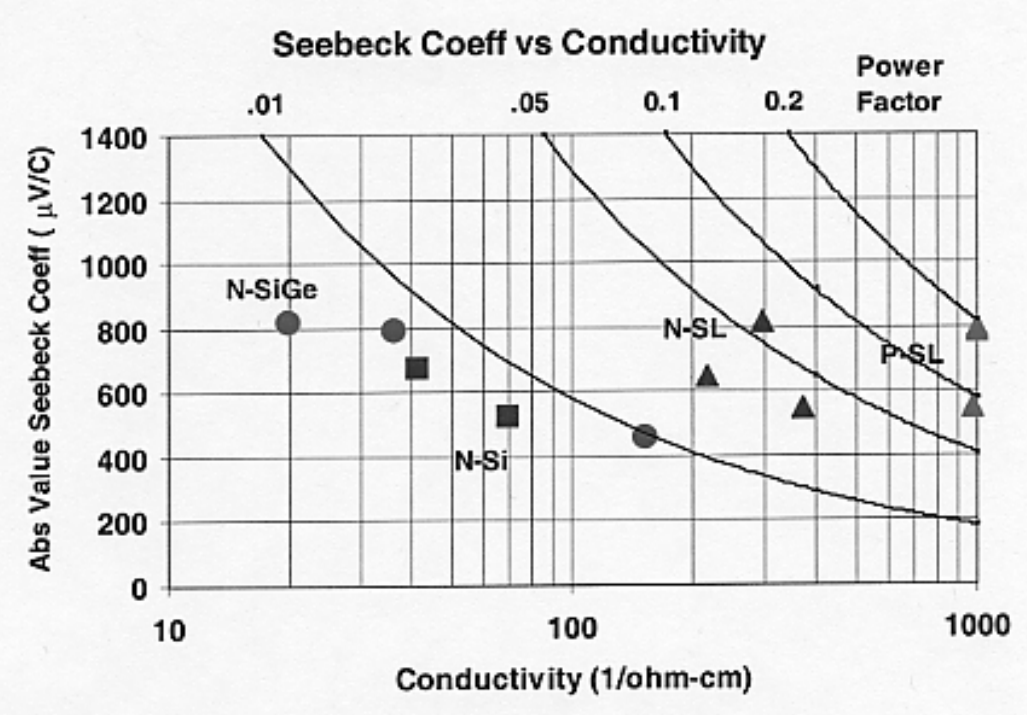

Figure 7. PNNL Experimental Results

\section{Purchase of Sputtering Machine}

The purchase order for the 34" sputtering machine was placed December 1, 2003. Progress payments have been made. A third progress payment in the amount of $\$ 128,920$ is expected to be made at a time of shop check-out in the fabricator's shop on or around May 31, 2004. The final payment of $\$ 32,230$ will be made upon operational checkout of the new sputtering machine in Hi-Z's facilities. Delivery of the machine is expected in June-July, 2004. DOE ORO's payment of the agreed $\$ 100,000$ share of the $\$ 322,300$ total cost of the machine was received in the first week of January. NETL's agreed share of $\$ 105,000$ was received January $16^{\text {th }}$. NASA's agreed share of $\$ 90,000$ was received April 8, 2004 NAVSEA's share amounting to $\$ 27,300$ will be billed to them in advance of the operational checkout and the final payment. The government funds awaiting the next disbursement to the fabricator are being held in a special interest-bearing money market account restricted to government funds.

\section{High Efficiency Thermoelectrics Workshop}

Hi-Z Technology presented a paper in the High Efficiency Thermoelectrics Workshop, Feb. 1720, 2004, in San Diego, sponsored by DOE. A copy of this presentation is attached. 